\title{
Abundance and biogeography of methanogenic and methanotrophic microorganisms across European streams
}

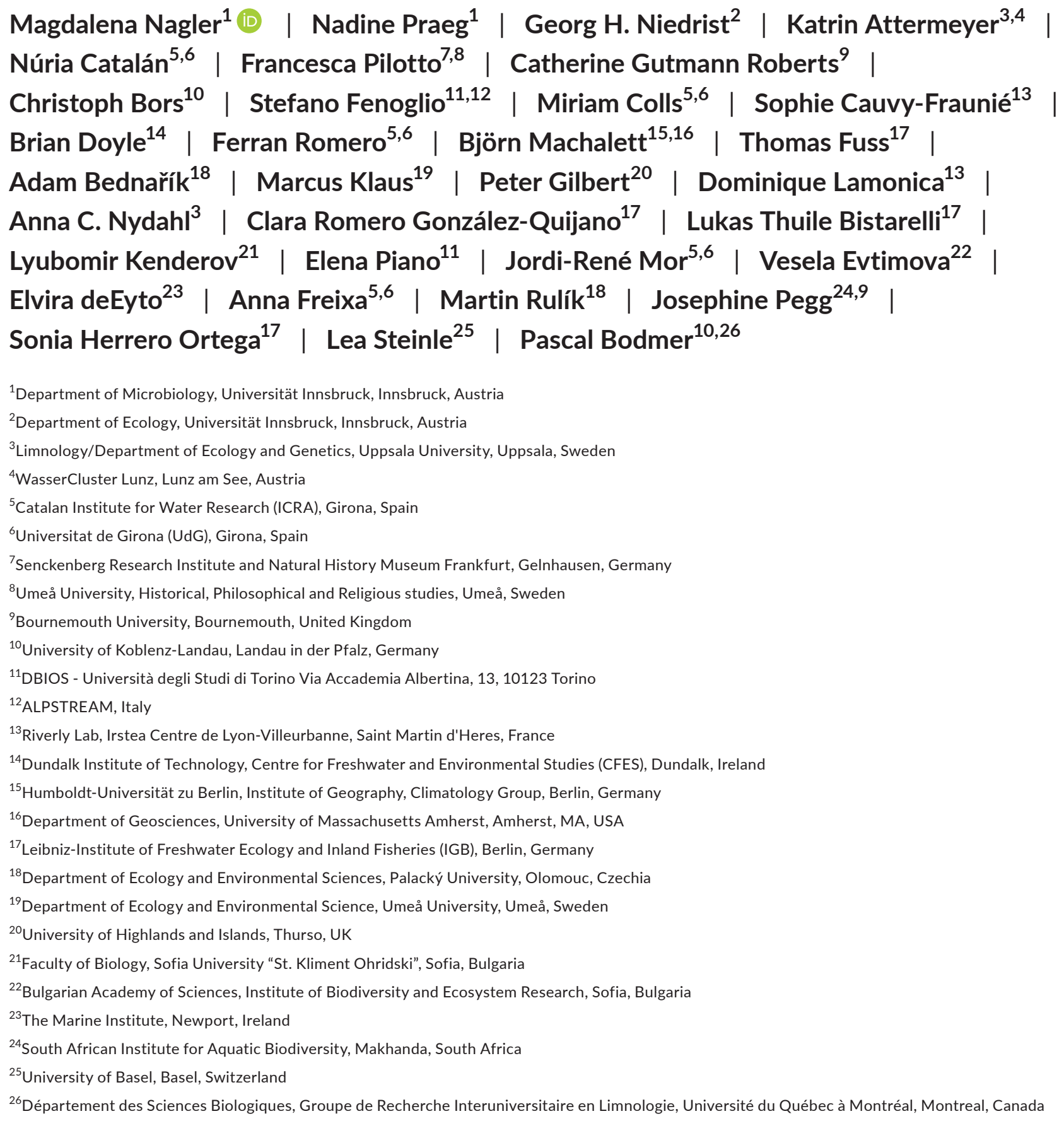




\section{Correspondence}

Magdalena Nagler, Universität Innsbruck, Department of Microbiology, Innsbruck, Austria.

Email: Magdalena.Nagler@uibk.ac.at

\section{Funding information}

German Research Foundation, Grant/Award Number: BO 5050/ and 1-1

Handling Editor: Jani Heino

\section{Abstract}

Aim: Although running waters are getting recognized as important methane sources, large-scale geographical patterns of microorganisms controlling the net methane balance of streams are still unknown. Here we aim at describing community compositions of methanogenic and methanotrophic microorganisms at large spatial scales and at linking their abundances to potential sediment methane production (PMP) and oxidation rates (PMO).

Location: The study spans across 16 European streams from northern Spain to northern Sweden and from western Ireland to western Bulgaria.

Taxon: Methanogenic archaea and methane-oxidizing microorganisms.

Methods: To provide a geographical overview of both groups in a single approach, microbial communities and abundances were investigated via 16S rRNA gene sequencing, extracting relevant OTUs based on literature; both groups were quantified via quantitative PCR targeting mcrA and pmoA genes and studied in relation to environmental parameters, sediment PMP and PMO, and land use.

Results: Diversity of methanogenic archaea was higher in warmer streams and of methanotrophic communities in southern sampling sites and in larger streams. Anthropogenically altered, warm and oxygen-poor streams were dominated by the highly efficient methanogenic families Methanospirillaceae, Methanosarcinaceae and Methanobacteriaceae, but did not harbour any specific methanotrophic organisms. Contrastingly, sediment communities in colder, oxygen-rich waters with little anthropogenic impact were characterized by methanogenic Methanosaetaceae, Methanocellaceae and Methanoflorentaceae and methanotrophic Methylococcaceae and $\mathrm{Cd}$. Methanoperedens. Representatives of the methanotrophic Crenotrichaceae and Methylococcaceae as well as the methanogenic Methanoregulaceae were characteristic for environments with larger catchment area and higher discharge. PMP increased with increasing abundance of methanogenic archaea, while PMO rates did not show correlations with abundances of methane-oxidizing bacteria.

Main conclusions: Methanogenic and methanotrophic communities grouping into three habitat types suggest that future climate- and land use changes may influence the prevailing microbes involved in the large-scale stream-related methane cycle, favouring the growth of highly efficient hydrogenotrophic methane producers. Based on these results, we expect global change effect on PMP rates to especially impact rivers adjacent to anthropogenically disturbed land uses.

\section{KEYWORDS}

inland waters, methane-oxidizing bacteria, methanogenic archaea, potential methane oxidation, potential methane production, stream sediments

\section{1 | INTRODUCTION}

Methane $\left(\mathrm{CH}_{4}\right)$ has a global warming potential 34 times higher than carbon dioxide $\left(\mathrm{CO}_{2}\right)$ (Ciais et al., 2013) due to its efficiency in absorbing infrared radiation (Etminan et al., 2016). While sources of $\mathrm{CH}_{4}$ are manifold and may be natural or anthropogenic, current estimates suggest that $35 \%-50 \%$ of global $\mathrm{CH}_{4}$ emissions originate from natural sources (Ciais et al., 2013). Among these sources, natural wetlands are the largest, followed by geological sources and freshwaters (running waters and lakes), with running waters contributing $3 \%$ of the global release or $15 \%-40 \%$ of the efflux from wetlands and lakes (Stanley et al., 2016).

Biogenic $\mathrm{CH}_{4}$ is almost exclusively produced by methanogenic archaea (MA) during the final step of anaerobic degradation of organic matter. $\mathrm{MA}$ mainly produce $\mathrm{CH}_{4}$ either from $\mathrm{H}_{2}$ and $\mathrm{CO}_{2}$ (hydrogenotrophic pathway) or from acetate cleavage (acetoclastic 
FIGURE 1 Conceptual figure of the sampling design at European, stream reach and site-specific scale. $\mathrm{PMP}=$ samples retrieved for potential methane production measurements, $\mathrm{PMO}=$ samples retrieved for potential methane oxidation measurements, DNA = samples retrieved for qPCR and sequencing. Map in Lambert Conformal Conic projection [Colour figure can be viewed at wileyonlinelibrary.com]
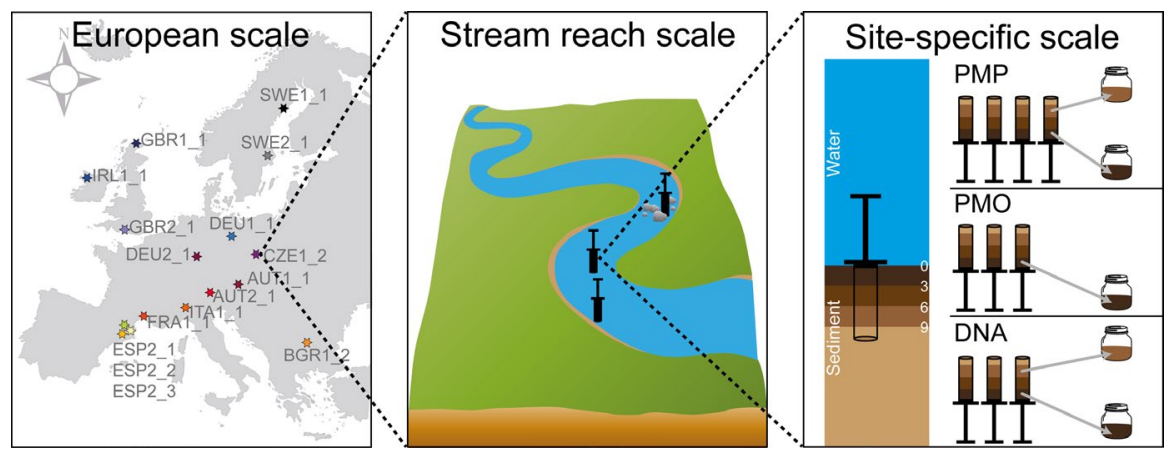

pathway) (Nazaries et al., 2013). Lotic waters represent important components of the global carbon cycle through carbon mineralization into $\mathrm{CO}_{2}$ and $\mathrm{CH}_{4}$ (Stanley et al., 2016) and first studies on river sediments revealed the dominance of Methanosarcinales and Methanomicrobiales (Chaudhary et al., 2017).

Environments facilitating the occurrence of communities producing $\mathrm{CH}_{4}$ are also typical habitats for methane-oxidizing microorganisms (MOX) (Kalyuzhnaya et al., 2019), which consume the newly synthesized $\mathrm{CH}_{4}$ as a carbon and energy source. Some MOX belong to archaea, perform anaerobic methane oxidation (ANME) and involve three distinct methanotrophic groups. Of these groups (ANME-1 to ANME-3), ANME-2 is further divided into four subgroups ANME-2 a, b, c, and Candidatus ( $C$ d.) Methanoperedens (Boetius et al., 2000). Furthermore, anaerobic $\mathrm{CH}_{4}$ oxidation can be performed by several bacterial species belonging to the phylum NC10 (Ettwig et al., 2010). Aerobic $\mathrm{CH}_{4}$ oxidation, however, is carried out by a heterogeneous group of obligate or facultative methanotrophic bacteria (MOB) usually divided into three main types: Gammaproteobacteria (type I or type X), Alphaproteobacteria (type II) and Verrucomicrobia (type III), all with different pathways of utilizing $\mathrm{CH}_{4}$ (Kalyuzhnaya et al., 2019). Aerobic MOX, often inhabiting anoxic-oxic interfaces such as the upper sediment layers, are known to support a high potential for $\mathrm{CH}_{4}$ oxidation in riverbeds (Trimmer et al., 2015). Furthermore, a large-scale study on methanotrophic communities in boreal inland waters in Canada highlighted a clear niche differentiation between type I and type II methanotrophs in water and river sediments (Crevecoeur et al., 2019). Besides these works on specific groups, however, the taxonomic composition/distribution of both, methanogens and methanotrophs and the respective predominant key players in different streams across ecoregions have not yet been examined.

While molecular approaches are helpful in analysing community compositions and abundances of MA and MOX, studying the net $\mathrm{CH}_{4}$ balance of an ecosystem also requires the quantification and investigation of $\mathrm{CH}_{4}$ production and oxidation processes. Studies measuring potential methane production (PMP) in streams, rivers (Bednařík et al., 2017) or river impoundments (Wilkinson et al., 2019) are scarce and do not necessarily link PMP rates with MA abundances. However, some recent studies on PMP in stream sediments (Chaudhary et al., 2017; Mach et al., 2015) reported two depthrelated PMP maxima along sediment profiles dominated by hydrogenotrophic methanogenesis. While these studies could not prove a relationship between MA abundance and PMP, others (Crawford et al., 2017) observed highest PMP rates in sediments enriched in the methane-producing mcrA-gene. Data on potential $\mathrm{CH}_{4}$ oxidation (PMO) in freshwater ecosystems are also scarce (e.g. Oswald et al., 2015), but it was shown that PMO from river sediments increased with decreasing gravel size (Bodmer et al., 2020). Additional drivers of such distributions and rates in stream sediments have not been identified so far.

To our knowledge, an in-depth investigation of taxonomic distributions and abundances of both microbial groups involved in the $\mathrm{CH}_{4}$ cycle and of underlying environmental conditions has not been carried out on large continental (European) scale. Thus, the present study aims to (a) describe the biogeography of MA and MOX in stream sediments, (b) identify the dominant species within each functional group, (c) examine the links between environmental conditions and the distribution of both MA and MOX and (d) compare the absolute abundances of MA and MOX with their potential metabolic activities across 16 European streams.

\section{MATERIALS AND METHOD}

\section{1 | Sampling design}

We sampled sediments from 16 streams across 10 European countries (Table S1, Appendix S2), using the EuroRun network (Bodmer et al., 2019; Bravo et al., 2018). Within a representative $50 \mathrm{~m}$ section of the investigated stream three patches were sampled based on their sediment grain size: (a) coarse (gravel, $>0.2 \mathrm{~cm}$ to $2 \mathrm{~cm}$ ), (b) medium (sand/mud, $>6 \mu \mathrm{m}$ to $2 \mathrm{~mm}$ ), and (c) fine (silt/loam/clay, $<6 \mu \mathrm{m}$; Figure 1). If not applicable, sediment patches with the widest range of sediment grain size were selected (coarse, medium and fine sediment). Particle size distributions were additionally measured in the laboratory to assure for a comparability of the categories across the streams. In most cases, the categories did not completely match with the measured grain sizes and, therefore, the three areas were considered as replicates of the same stream. Sediment surface area (measured) was used as parameter describing the within-stream sediment heterogeneity (see chapter 2.2.)

From each of the three stream replicates (patches), 10 sediment cores were sampled with cut-off $100 \mathrm{~mL}$ syringes (diameter: $3.6 \mathrm{~cm}$ ), avoiding sediment vertical profile disturbance or compression. To 
gain insight into microbial spatial preferences resulting from oxygen availability, cores were split into two samples from different depths $(0-3 \mathrm{~cm}$ and $6-9 \mathrm{~cm}$ below the surface water interface), and transferred to $30 \mathrm{~mL}$ glass vials. Samples were stored at $4^{\circ} \mathrm{C}$ and shipped to the respective laboratories (University of KoblenzLandau, Germany: PMP, sediment nitrogen and organic carbon content; University of Basel, Switzerland: PMO; University Innsbruck, Austria: molecular work) the following day. Three parallel samples of each sediment layer per patch were combined to form one composite sample of each depth, and an aliquot was taken for DNA extraction ( $n=96$; stored at $-20^{\circ} \mathrm{C}$; processed 7-21 days after sampling; Figure 1). Furthermore, three $0-3 \mathrm{~cm}$ sediment samples per sediment patch were used for PMO measurements ( $n=144$; stored at $3^{\circ} \mathrm{C}$; processed $5-8$ days after sampling), and both sediment layers of four sediment samples per patch were used for PMP measurements $\left(n=384\right.$; stored at $4^{\circ} \mathrm{C}$; processed $3-10$ days after sampling; Figure 1)

\subsection{Physical and chemical parameters}

The upstream catchment area, elevation (metres above sea level), Strahler stream order (Strahler, 1952), and land use within the catchment were taken from Bravo et al. (2018), which covered the same sites (Table S1, Appendix S2). Land use within the catchment was further simplified after inspection via principal component analysis (PCA; see section 2.7) by unifying the classes 'urban' and 'agriculture as well as 'forest' and 'others' into 'anthropogenically altered' and 'natural' respectively. As those two variables represented co-correlating values, only 'natural' was used for those analyses influenceable by correlating descriptor variables (i.e. redundancy analysis; RDA and generalized linear mixed models; GLMMs). Besides these landscape variables, hydromorphological features were measured with standard methods (see Method S1, Appendix S3), including wetted stream width $(\mathrm{m})$, cross-sectional area $\left(\mathrm{m}^{2}\right)$, water depth $(\mathrm{m})$, stream area $\left(\mathrm{m}^{2}\right)$, discharge $\left(\mathrm{m}^{3} \mathrm{~s}^{-1}\right)$, mean flow velocity $\left(\mathrm{ms}^{-1}\right)$ and channel slope (\%).

Physical and chemical parameters $(\mathrm{pH}$, surface water oxygen concentration $[\mathrm{mg} / \mathrm{L}]$, conductivity $\left[\mu \mathrm{Scm}^{-1}\right]$ and temperature $\left[{ }^{\circ} \mathrm{C}\right]$ ) were measured with standard methods during daytime in the middle of the stream (Table S2, Appendix S2 for devices used at individual sites).

Particle size distribution was measured from a subsample of each PMP sample at the Thuringian Particle Size Laboratory using a Beckman-Coulter LS 13,320 PIDS following (Machalett et al. 2008; Method S2, Appendix S3). To estimate the area potentially colonizable by microorganisms, sediment surface area $\left(\mathrm{cm}^{2} \mathrm{~cm}^{-3}\right)$ was calculated using the mean size of each particle class assuming a spherical particle shape.

Sediment nitrogen and organic carbon content (expressed as weight percent of dry sediment) was measured from PMP samples after the incubation period by dry combustion (Vario MICRO Cube, Elementar Analysensysteme $\mathrm{GmbH}$ ), assuming the consumption under anoxic conditions in this period of time to be negligible (Method S3, Appendix S3).

\section{3 | Potential methane production and potential methane oxidation}

PMP was measured according to Wilkinson et al. (2019) and PMO according to Steinle et al. (2016) and Su et al. (2019). In brief, for PMP, the sediment was incubated for 5 weeks in an air-tight vial at $16^{\circ} \mathrm{C}$ in the dark. Headspace gas samples were analysed weekly with an ultraportable greenhouse gas analyser and PMP was calculated from the linear increase in $\mathrm{CH}_{4}$ partial pressure over time $\left(\mathrm{g} \mathrm{CH}_{4} \mathrm{~m}^{-3}\right.$ fresh sediment $\mathrm{d}^{-1}$ ).

For $\mathrm{PMO}$, fresh sediment samples were amended with trace amounts of ${ }^{14} \mathrm{C}$-labelled aqueous $\mathrm{CH}_{4}$ and incubated in the dark for $\sim 3$ days at room temperature. Incubations were stopped with $20 \mathrm{~mL}$ $2.5 \%$ sodium hydroxide and $\mathrm{PMO}\left(\% \mathrm{CH}_{4} \mathrm{~d}^{-1}\right)$ was assessed by ${ }^{14} \mathrm{CH}_{4}$ combustion and ${ }^{14} \mathrm{CO}_{2}$ acidification. Further details are given in the supplement (Method S4, Appendix S3).

\section{4 | DNA extraction}

DNA was extracted from approx. $500 \mathrm{mg}$ fresh composite sediment sample for each depth using the Nucleo Spin ${ }^{\circledR}$ Soil Kit (MachereyNagel). DNA quality was checked on $1 \%(w / v)$ agarose gels using GelGreen $^{\text {TM }}$ staining (Biotium Inc.,) and quantity was measured using a Quantus ${ }^{\mathrm{TM}}$ Fluorometer and the QuantiFluor ${ }^{\circledR}$ Dye System for double-stranded DNA (dsDNA; Promega).

\section{$2.5 \mid \mathrm{qPCR}$}

Quantitative PCR (qPCR) was conducted using the SensiFast ${ }^{T M}$ SYBR No-Rox Kit (Bioline, UK) on a Corbett Life Science RotorGeneTMQ system (Qiagen). Total mcrA-genes of MA were determined using the primer set mlas/mcrA-rev (469bp) (Steinberg and Regan, 2009) and the abundance of pmoA gene of type la and type II methane-oxidizing bacteria with the primer pairs A189f/Mb601r (432bp) and II223f/II646r (444bp) (Kolb et al., 2003; Cai et al., 2016; Praeg et al., 2020; see Table S3, Appendix S2 for cycling conditions). Detailed qPCR-related information is given in the supplement (Method S5, Appendix S3). In contrast to the sequencing, the qPCR approach does not include ANME and the quantified group targeted with the $p m \circ A$ is thus abbreviated as MOB (without archaea). Thereby, the separate investigation of type I and type II MOB provides (more) detailed information on methanotrophic physiology (Trimmer et al., 2015) and total methanotrophs can be quantified to a large extend by the aforementioned primer pairs (Cai et al., 2016; Kolb et al., 2003; Praeg et al., 2020). Thus, gene copies of type la and type II MOB were summed to represent an approximation to the total MOB gene copy number. 


\section{6 | $16 \mathrm{~S}$ rRNA gene sequencing and bioinformatics}

For this first study investigating the biogeography and diversity of all microorganisms driving the $\mathrm{CH}_{4}$ cycle within stream sediments across Europe, we sequenced the 16S rRNA gene as a target, providing a broad overview of all present microbial taxa including MA and MOX in equal measure. The gained rarefaction curves (Figure S1, Appendix S1) exhibited a high depth of 16S rRNA gene sequencing suitable for in-depth interpretation. Although targeting of functional marker genes might yield more informative sequence reads, the used primer set makes the results highly comparable to existing $16 \mathrm{~S}$ rRNA-based studies and a careful interpretation of the results offers noticeable first insights on the diversity of methanogens and methanotrophs across European stream sediments.

A total of 96 DNA extracts resulting from (composite) triplicates of 16 streams and two depths was subjected to high-throughput amplicon sequencing on an Illumina MiSeq platform (v2) performing a $300 \mathrm{bp}$ paired-end run and simultaneously targeting bacteria and archaea via the $\mathrm{V} 4$ region of the 16S SSU rRNA gene (StarSEQ) using the 515f/806r primer system (Caporaso et al., 2011).

Sequence data were processed applying the CoMA pipeline, a pipeline for amplicon sequencing data analysis based on various applications such as Qiime, Mothur and others (Hupfauf et al., 2020). In brief, merging of paired-end reads and trimming of barcodes and primers were done using the recommended settings. High-quality reads were selected to show $<5 \%$ deviation from the mode sequence length and at least $99.7 \%$ base call accuracy (phred score $\geq 25$ ). Sequences were aligned applying a $97 \%$ similarity level and assigned taxonomically using the blast algorithm against SILVA SSU (release 132) and Greengenes (release 13_5) as primary and backup databases respectively. Operational taxonomic units (OTUs) represented by only one read within all samples were excluded and samples were subsampled to 73'249 reads after rarefaction analysis, thereby dropping two samples (FRA1_1_2_B and FRA1_1_2_C) with considerably lower read numbers (37'630 and 34'099 reads, respectively). After even-sampling, OTUs assigned to MA and methane-oxidizing microorganisms (containing both, archaea and bacteria and therefore abbreviated as MOX) as listed in recent literature (Kalyuzhnaya et al., 2019; Nazaries et al., 2013) were extracted and used for subsequent analyses.

\section{7 | Data analysis}

\subsection{1 | Environmental data}

To reduce the dimensions of the multivariate dataset and explore the environmental conditions of the streams, a PCA was performed using the FactoMineR and factoextra packages (Kassambra \& Mundt, 2017; Lê et al., 2008; R Core Team, 2018).

\subsection{2 | Community data}

Differences among the community structure of all sequenced OTUs from different sediment depths $(0-3 \mathrm{~cm}, 6-9 \mathrm{~cm})$ and variation in community composition as a function of stream and depth were tested with one-way and two-way PERMANOVA (using Adonis function) with 9,999 permutations, based on Bray-Curtis dissimilarity matrix of both MA and MOX communities using the vegan package (Oksanen et al., 2019). As sampling depth had no significant influence on the community composition of MA or MOX, subsequent analyses were performed on sequencing data of both sampling depths combined ( $n=96$ ); $\alpha$-diversity was inspected calculating Shannon index and OTU richness (Chao-index) using the Mothur software pipeline v.1.39.0 (Schloss et al., 2009) and averaging their distribution on family-level in each stream (i.e. combining the three composite samples per sediment depth of the three sampled patches). The top 5 families in each stream were determined by calculating mean ranks of all families, and $\beta$-diversities were studied performing an NMDS with Bray-Curtis dissimilarities on OTU-level of MA and MOX including both sediment layers.

Univariate relationships between log-transformed relative read numbers of MA and MOX families with each other and with environmental variables were examined with Pearson correlation tables using the corrplot package and a significance level of $1 \%$ (Wei et al., 2017). Correlation between environmental variables and MA and MOX communities were determined via redundancy analyses (RDA) with 499 unrestricted permutations on log-transformed read numbers using the default interactive forward selection mode in Canoco5 (Šmilauer \& Lepš, 2014), considering only one representative of each co-correlating group of environmental variables (identified in the PCA, see above).

\subsection{3 | Gene abundance data}

Relationships between abundance of MA and MOB, between PMP and $\mathrm{MA}$, and between $\mathrm{PMO}$ and $\mathrm{MOB}$ were explored using generalized linear models (GLMs) on log-transformed data. Differences in gene copy numbers at different depths were tested using pairwise comparisons (paired student's $t$ test) in all technical replicate samples with the package ggpubr (Kassambra, 2018). Since the depth effect was negligible (small significant effect for MOX only, see results section 3.5), both depth levels were combined for subsequent analyses. Differences of gene copy numbers between individual streams were evaluated using Kruskal-Wallis rank sum test and best correlating stream-scale variables were identified with GLMs on the data aggregated by stream $(n=16)$ with forward selection based on Bayesian information criterion, using a log link function and considering multicollinearity between predictors. Generalized linear mixed models (GLMMs) were used to disentangle the sitespecific environmental drivers of MA and $\mathrm{MOB}$ gene copy numbers, while considering stream-scale differences $(n=96)$. Hence, stream 
identity was considered as a random effect and the following sitespecific variables were included as fixed effects: sediment nitrogen and organic carbon content, sediment surface area, and sediment $\mathrm{C}: \mathrm{N}$ ratio. Various models with different combinations of fixed effects were constructed using the packages Ime4 (Bates et al., 2015) and r2glmm (Jaeger, 2017), while avoiding multicollinearity (checked using the package corrplot; Wei et al., 2017). The final GLMM for the two dependent microbial communities (MA and $\mathrm{MOB}$ ) was selected based on the GLMMs fit by examining both the mixed effect models conditional $\mathrm{R}^{2}$ (Nakagawa \& Schielzeth, 2012) and the prediction quality of gene copy numbers (correlation between observed and predicted gene copies). The importance of each environmental variable was evaluated using the percentage of explained variation.

\section{3 | RESULTS}

\section{1 | Environmental data}

The PCA (Figure 2; Tables S1, S4 in Appendix S2) revealed the influence of hydromorphological stream characteristics and physicochemical water properties on the first axis (Figure 2). The second axis discriminated the samples based on grain size distributions and sediment organic carbon content. Axis 1 ordered samples according to site and latitude and axis 2 separated different sediment types within streams (i.e. coarse, medium and fine sediment patches).

\subsection{Alpha- and beta-diversity of MA and MOX communities in streams across Europe}

Total 16S rRNA read numbers ranged from 73 '249 to 140 '000 per sample. Of all reads, a mean of 728 (1.0\%) belonged to MA and 799 (1.1\%) to MOX. There were no significant differences in overall microbiome composition of all sequenced operational taxonomic units (OTUs; including all bacteria and archaea) between samples from 0-3 $\mathrm{cm}$ and 6-9 $\mathrm{cm}$ sediment depths, as tested with PERMANOVA.

MA reads were assigned to 11 families, with Methanoregulaceae, Methanosaetaceae, Methanosarcinaceae and Methanobacteriaceae being relatively most abundant (Figure $3 a, c$ ), based on the number of reads. MA diversity ranged from 10 to 33 OTUs and over a Shannon index from 1.6 to 2.9 (Figure 3a; Table S5 in Appendix S2). MA species richness and diversity were positively correlated with water temperature (Pearson`s $r=0.45, p<0.01$ ) and catchment area (Pearson's $r=0.48, p<0.01$ ), respectively, while they were negatively correlated with increasing natural land cover percentages within the catchment $(r=-0.48$ and $r=-0.5$, resp., $p<0.01$; Figure S2 in Appendix S1).

For MOX, OTUs were assigned to eight different families, with bacterial Methylococcaceae, unclassified Methylococcales, Methylocystaceae, $\mathrm{Cd}$. Methylomirabilis and the archaeal clade $\mathrm{Cd}$. Methanoperedens being most abundant (Figure 3b,d; Table S5, Appendix S2). Within MOX, significant differences in read numbers between both sampling depths $(0-3$ versus. 6-9 cm) were found for $C d$. Methanoperedens as well as $C d$. Methylomirabilis, yielding higher relative abundances in deeper sediment samples (Mann-Whitney $\mathrm{U}, p<0.01$, Table S5, Appendix S2). For other families including Methylocystaceae, CABC2E06, Crenotrichaceae and pIW-20, differences were less pronounced $(p=0.014, p=0.017, p=0.034$ and $p=0.023$, respectively), but all families displayed lower read numbers in the deeper sediment layer. Similarly, read numbers of anaerobic methane oxidizers (i.e. the sum of $\mathrm{Cd}$. Methanoperedens $+\mathrm{Cd}$. Methylomirabilis reads) were significantly higher within the deeper sediment layer (Mann-Whitney $U, p<0.01$ ), while read numbers of aerobic methane oxidizers did not differ significantly between both sampling depths. MOX OTU numbers ranged from 12 to 64 and diversities from 0.5 to 2.7 , with diversity being significantly correlated with geographical latitude (Pearson`s $r=-0.51, p<0.01$ ), stream area (Pearson's $r=0.51, p<0.01$ ), wetted stream width (Pearson's $r=0.49, p<0.01$ ) and channel slope (Pearson`s $r=0.46, p<0.01$,

Figure S2, Appendix S1).

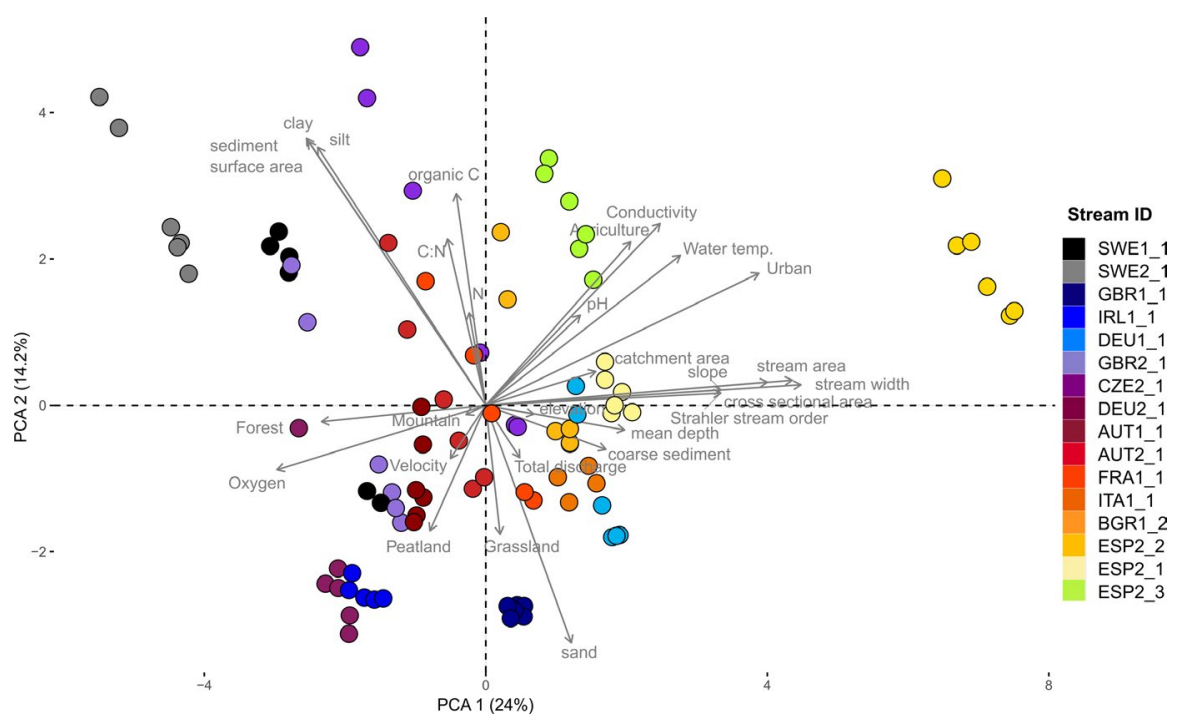

FIGURE 2 Principal component analysis plot of the first two dimensions based on all combined environmental data collected at two depths $(0-3$ and 6-9 cm depth) of three patches in each stream. Sample sites are coloured according to geographical latitude with SWE1_1 representing the northernmost and ESP2_3 the southernmost sampling points. Further information about units is listed in Tables S1 and S4 in Appendix S2. Proportions of explained variance of both dimensions are given in brackets [Colour figure can be viewed at wileyonlinelibrary. com] 

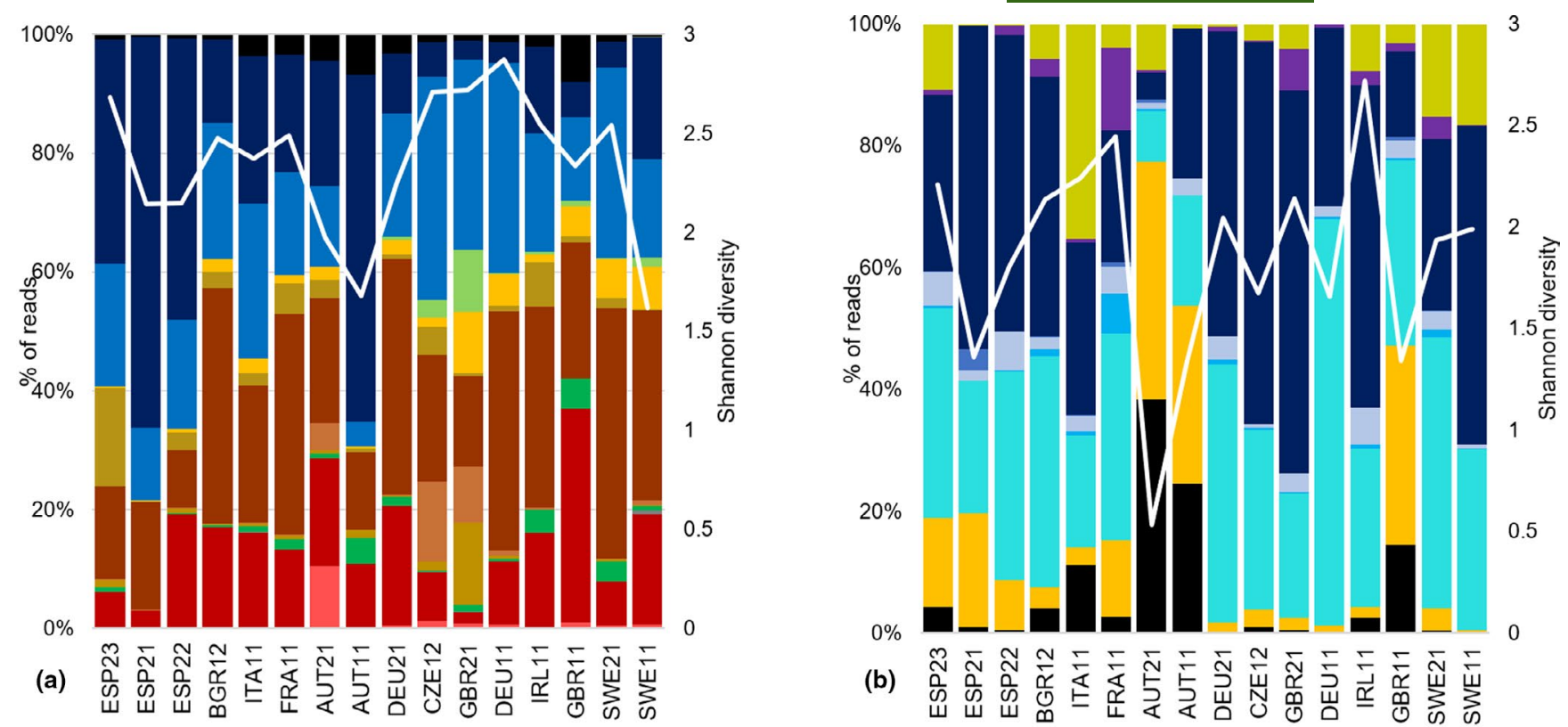

(b)

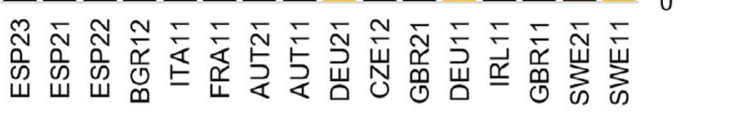

\begin{tabular}{ll} 
Order & Family \\
\hline Thermoplasmata & Incertae Sedis \\
\hline Methanosarcinales & Methanosarcinaceae \\
& Methanosaetaceae \\
\hline Methanomicrobiales & Cd. Methanoflorentaceae \\
& MHLsu47-B8A \\
& Methanospirillaceae \\
& Methanoregulaceae \\
& Methanomicrobiaceae \\
& unclassified \\
\hline Methanocellales & Methanocellaceae \\
\hline Methanobacteriales & Methanobacteriaceae \\
\hline Unclassified Methanomicrobia
\end{tabular}

\begin{tabular}{ll}
\hline Order & Family \\
\hline Methanosarcinales & Cd. Methanoperedens \\
\hline Methylococcales & $\mathrm{pLW}-20$ \\
& Methylococcaceae \\
& Marine Methylotrophic group \\
& Crenotrichaceae \\
& CABC2E06 \\
& unknown \\
\hline Rhizobiales & Methylocystaceae \\
\hline Nitrospirales & Cd. Methylomirabilis \\
\hline
\end{tabular}

Unclassified Methanomicrobia

(c)

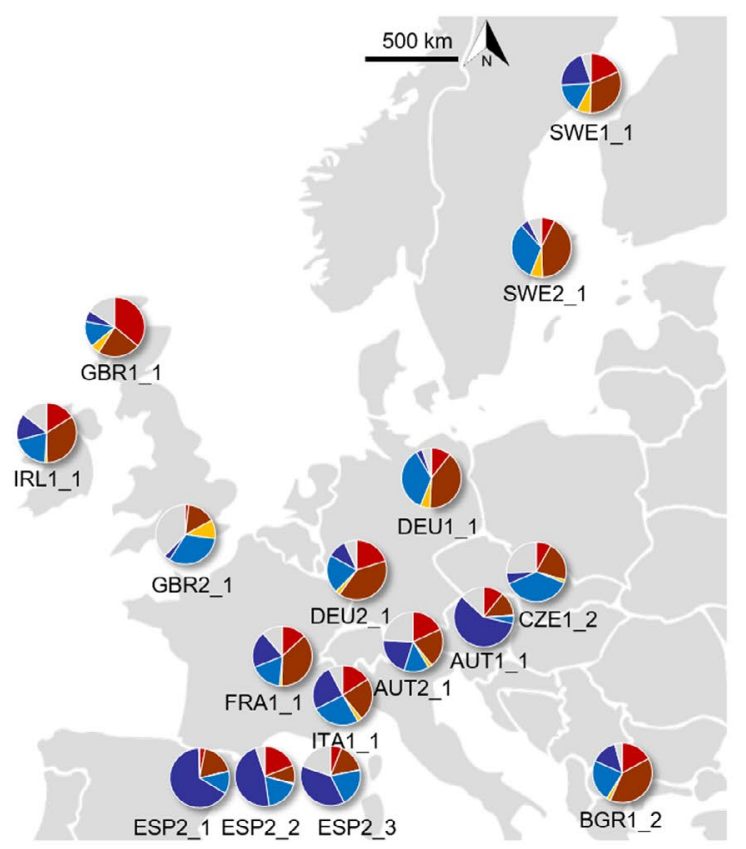

(d)

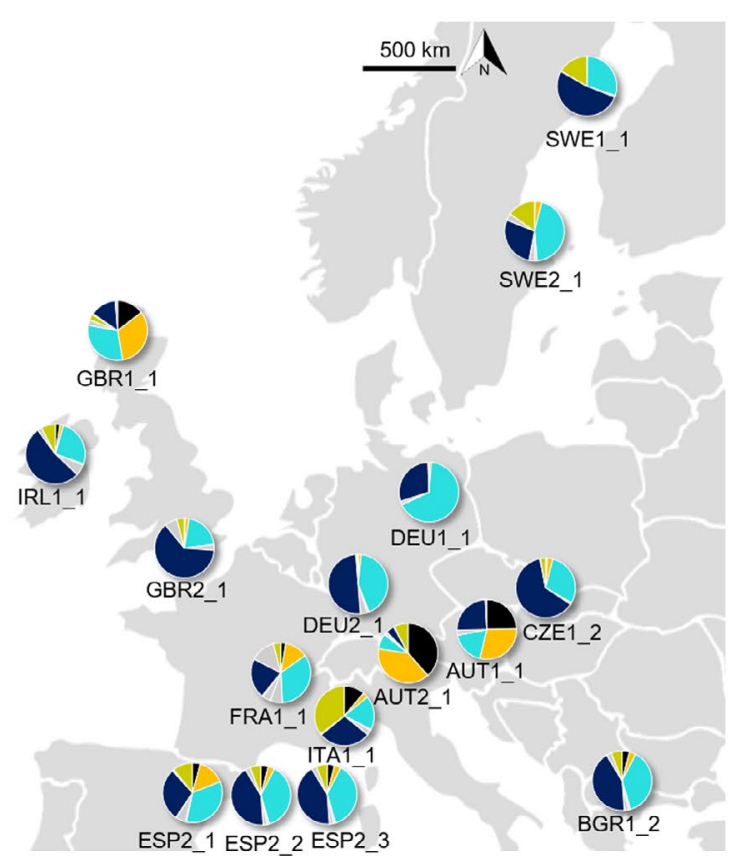

FIGURE 3 Mean biogeography of (a,c) methanogenic archaea (MA) and (b,d) methane-oxidizing bacteria and archaea (MOX) based on combined data from 0 to 3 and from 6 to $9 \mathrm{~cm}$ sediment depth in streams across Europe. a) and b) show relative $\alpha$-diversities at family level with sampling sites ordered by geographical latitude. The line represents the Shannon Index. (c and d) show the top 5 families across European streams selected by mean rank of each family among all sites. Pie charts show percentages of reads belonging to MA or MOX. Map in Lambert Conformal Conic projection [Colour figure can be viewed at wileyonlinelibrary.com] 


\section{3 | Correlations among taxonomic groups and with environmental variables}

The separation of communities via NMDS illustrated a more homogeneous composition of MA compared to MOX. The latter formed clusters that are more distinct among sampling sites and roughly grouped according to their geographical latitude (Figure S3, Appendix S1), but both groups exhibited a wide range of withinstream variability, which is linked to both the sampling depth and patch-specific environmental constraints. According to the two-way PERMANOVA, the affiliation to a certain stream had a significant effect on both, MA and MOX (PERMANOVA, $p<0.01$ ), while the sampling depth was found to be marginally influential only for MOX (PERMANOVA, $p=0.032$ ) and no significant interaction effect was found.

The best (and significant) subset of the environmental variables to summarize the variation in species composition (identified via interactive forward selection in RDA) accounted for an adjusted explained variation of $39.5 \%$ (MA) and 55.4\% (MOX; Figure 4a,b). MA communities in more anthropogenically altered and warm environments with increased $\mathrm{pH}$ were represented by various Methanospirillum spp., by members of the family Methanosarcinaceae and by a variety

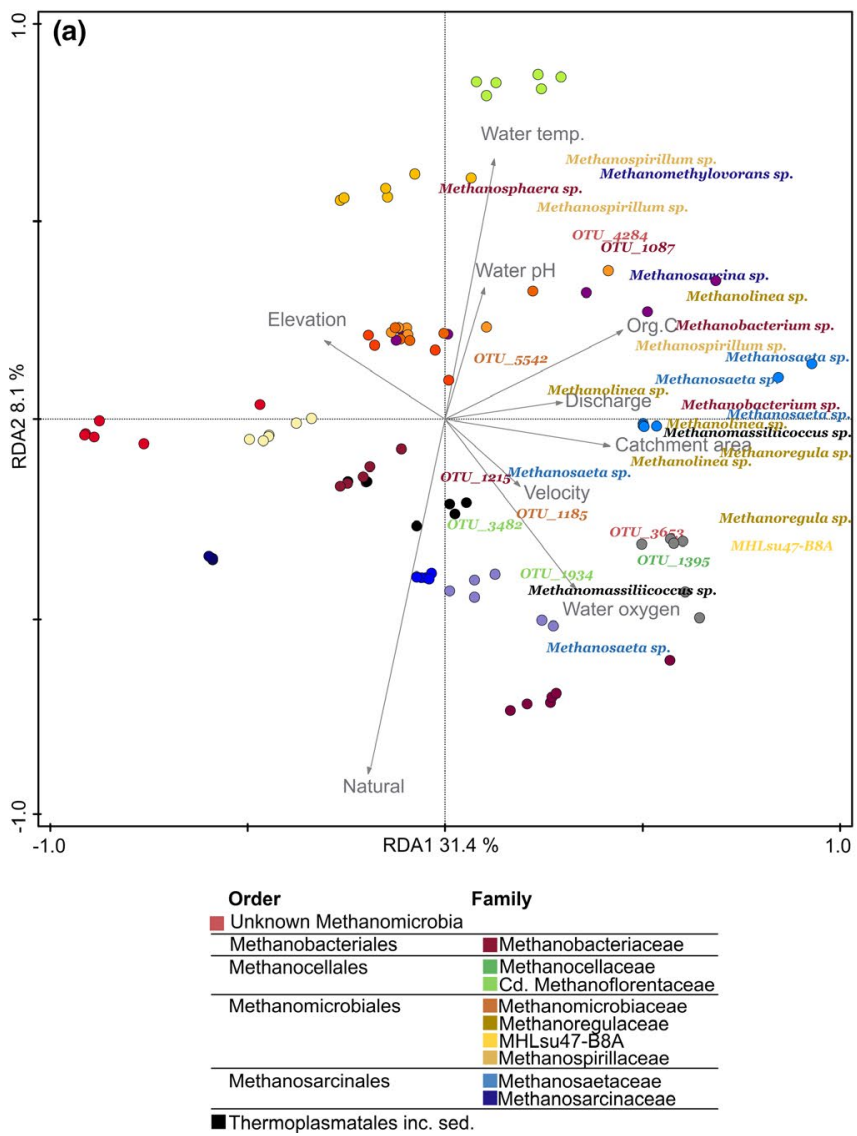

of taxa belonging to Methanobacteriaceae (Figure 4a), while no representative MOX community was established within comparable environments (Figure 4b).

Communities in well-oxygenated streams in natural land cover dominated catchments were characterized by MA groups Methanosaeta spp., Methanocellaceae and Methanoflorentaceae, and by many MOX of the family Methylococcaceae, of unassigned Methylococcales and, interestingly, by various $\mathrm{Cd}$. Methanoperedens (Figure 4a,b).

For both, MA and MOX, another well-separated community was also found in streams draining larger catchments with high discharge (mainly sampling site DEU1_1) featuring MA representatives Methanosaeta spp., Methanolinea spp. and Mehanoregula spp. and MOX representatives Methylocaldum spp. and Crenothrix spp. (Figure 4a,b).

Generally, relative read numbers of MA were mostly influenced by environmental parameters reflecting climatic conditions such as latitude and water temperature, while MOX read numbers correlated with surface water oxygen saturation and stream area (Figure S2a, Appendix S1). Moreover, identified positive and negative relationships within and between MA and MOX families are reflecting the grouping in the RDA (Figure S3, Appendix S1).

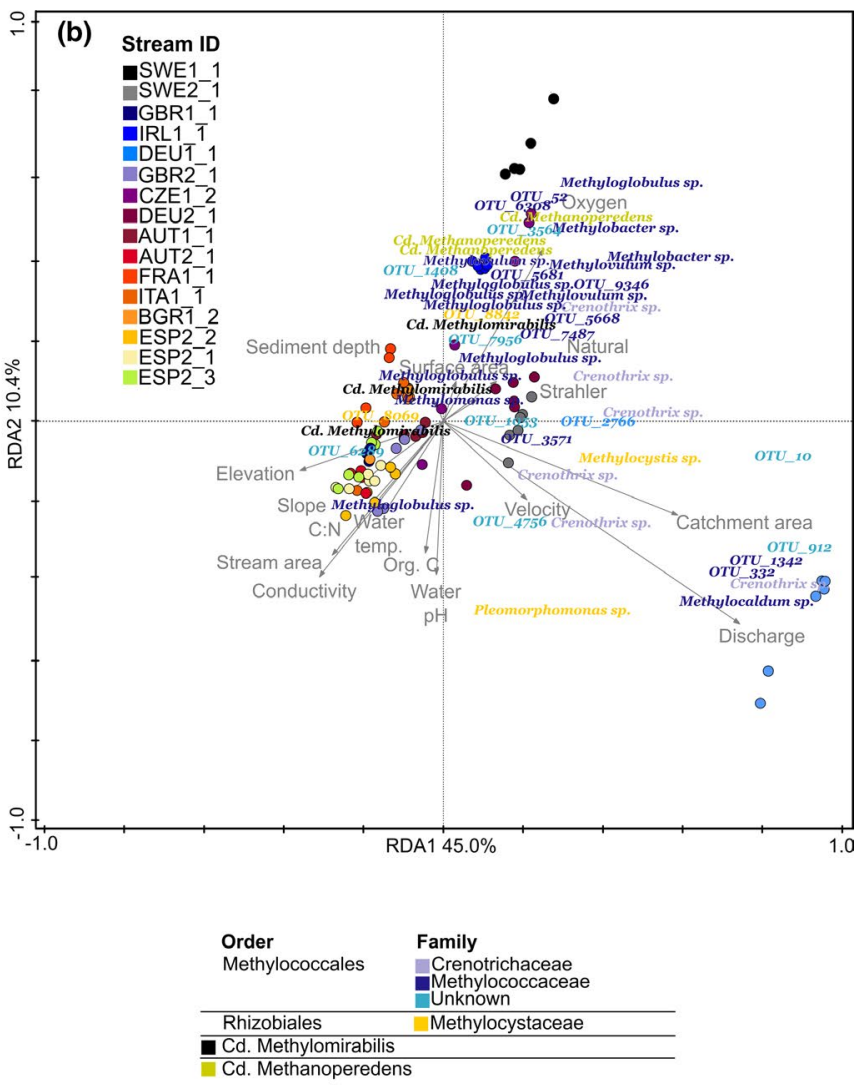

FIGURE 4 Triplots of redundancy analysis (RDA) of MA (top) and MOX (bottom) sequences from stream sediments in 0-3 and in 6-9 cm depth. Significant environmental parameters selected by forward selection are depicted and are grouping operational taxonomic units (OTU) as well as samples (sediment patch and depth) towards their predominant environmental characteristics and preferred habitats respectively. Explained variations of each axis are given as percentage of all eigenvalues. The stream-ID colour code refers to circles and the OTU colour code to labels [Colour figure can be viewed at wileyonlinelibrary.com] 


\subsection{Methane production and oxidation potentials}

PMP rates ranged from $9.7 \times 10^{-5} \mathrm{~g} \mathrm{CH}_{4} \mathrm{~m}^{-3} \mathrm{~d}^{-1}$ (IRL1_1) to $9.46 \mathrm{~g}$ $\mathrm{CH}_{4} \mathrm{~m}^{-3} \mathrm{~d}^{-1}$ (CZE1_2) and PMO rates from $1.7 \times 10^{-4} \% \mathrm{CH}_{4} \mathrm{~d}^{-1}$ (SWE1_1) to $0.32 \% \mathrm{CH}_{4} \mathrm{~d}^{-1}$ (IRL1_1; Table S5, Appendix S2). PMP rates did not differ significantly between both sediment depths, with mean values of $1.61 \pm 0.69$ at $0-3 \mathrm{~cm}$ and $0.56 \pm 1.58 \mathrm{~g} \mathrm{CH}_{4} \mathrm{~m}^{-3} \mathrm{~d}^{-1}$ at $6-9 \mathrm{~cm}$.

\subsection{Gene abundance data}

Abundance of mcrA-gene ranged from $3.1 \times 10^{1}$ to $3.2 \times 10^{7}$ gene copies $g$ fresh weight ${ }^{-1}$, type la $\mathrm{MOB}$ gene abundances from $2.82 \times 10^{2}$ to $2.55 \times 10^{7}$ and type II MOB from $5.98 \times 10^{2}$ to $6.8 \times 10^{7}$ gene copies g fresh weight ${ }^{-1}$ (Table S5, Appendix S2). While mean copy numbers of all genes were lower in the deeper sediment samples (mcrA: $2.6 \times 10^{6}$ versus. $2.5 \times 10^{6}$ type la: $3.3 \times 10^{6}$ versus. $2.1 \times 10^{6}$ type II: $4.3 \times 10^{6}$ versus. $2.1 \times 10^{6}$ ), the effect of sampling depth was not significant.

Gene copy numbers of mcrA-genes were correlated with both single $\mathrm{MOB}$-deriving gene abundances $\left(\mathrm{R}^{2}=0.670, p<0.001\right.$ for type la; $R^{2}=0.348, p<0.001$ for type II; Figure $\left.5 a, b\right)$ and to the cumulative MOB gene copy numbers $\left(R^{2}=0.594, p<0.001\right.$ Figure $5 c$ ), forming a LOG-LOG relationship. Similarly, mcrA-gene copy numbers showed a positive LOG-LOG correlation with PMP rates $\left(R^{2}=0.394, p<0.001\right.$, Figure $\left.5 d\right)$. A correlation between PMO rates and both $\mathrm{MOB}$-related gene abundances was not detected (Figure $5 \mathrm{e}, \mathrm{f}$ ).

Cumulative MOB gene copy numbers were significantly higher in upper sediment layers of each sample (paired Student's $t$ test, $p<0.01$, Figure S5, Appendix S1), although the difference was only marginal.

Gene abundances of MA and cumulative MOB differed among sampled streams (Kruskal-Wallis $\chi^{2}=59$ and 46, $p<0.05$ ), with higher numbers in streams draining larger catchment areas (linear model, $p<0.05$; Table S6, Appendix S2). Discharge correlated positively with catchment area and was therefore not considered as potential predictor. Within streams, the number of MA gene copies was positively related to sediment organic carbon content and sediment surface area, while $\mathrm{MOB}$ gene copies were positively related with sediment organic carbon content (Table S6, Appendix S2). Overall, the increasing explanatory power of GLMMs due to the inclusion of site-scale variables (increasing $\mathrm{R}^{2}$, from 0.55 to 0.65 for MA and
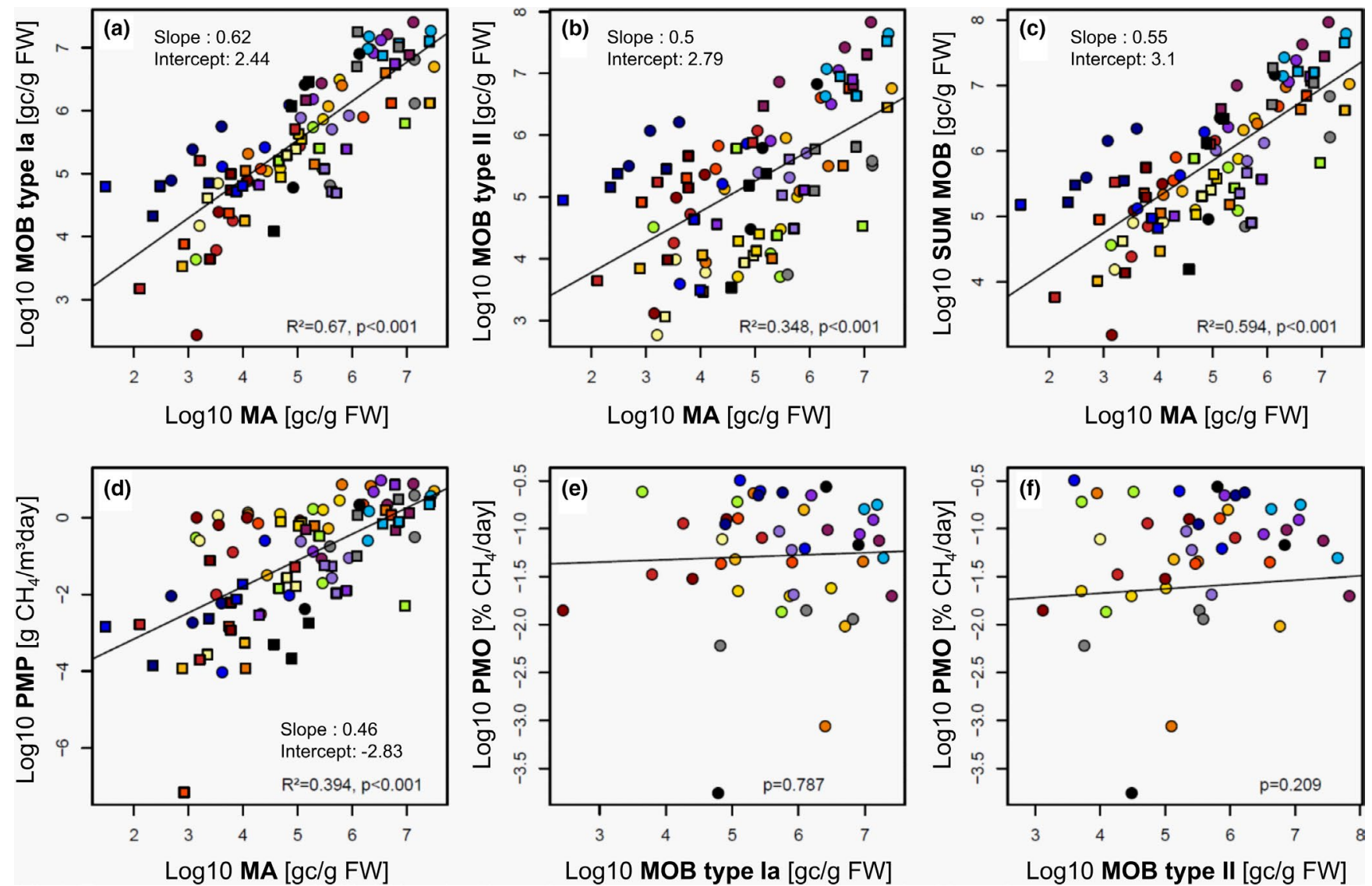

FIGURE 5 Correlations of log-transformed mcrA-gene abundances of methanogenic archaea and type la MOB (a), type II MOB (b), cumulative $\mathrm{MOB}(\mathrm{c})$ and potential methane production rates (PMP) (d). Relation of type la (e) and type II MOB (f) and potential methane oxidation rates $(\mathrm{PMO}) . \mathrm{MOB}=$ methane-oxidizing bacteria. $\mathrm{MA}=$ methanogenic archaea. Colours refer to sampled streams described in Figure 2, circles to sediments sampled at $0-3 \mathrm{~cm}$ depth and squares to sediments sampled at 6-9 $\mathrm{cm}$ depth. Slope and intercept of the fitted lines are only reported for significant $(p<0.05)$ relationships [Colour figure can be viewed at wileyonlinelibrary.com] 
from 0.44 to 0.54 for MOB; Table S6, Appendix S2) indicated positive correlations between gene copies and organic carbon content and/or surface area within streams, while the overall gene copy number differed among streams. No other parameter showed significant relationships with response measures, but nitrogen content was significantly correlated with organic carbon content and was therefore excluded from the model.

\section{DISCUSSION}

\section{1 | Environmental constraints}

A major interest in microbial ecology is the identification of biogeography, shaped by processes such as habitat filtering, dispersal, drift and mutation. In that context, we demonstrate a biogeographic pattern of methanotrophic and methanogenic communities associated with geographic dispersal and environmental influences, identify dominant taxa within each functional group, and compare the absolute abundance of MA and MOX with their potential activities within 16 stream sediments across a latitudinal and longitudinal distance of $2 ' 700 \mathrm{~km}$. Streams were separated in two groups based on environmental conditions (first PCA component, Figure 2). 'Environment 1 ' represents warm streams with large stream areas, high conductivity and low surface water oxygen concentrations, draining catchments with high proportions of agricultural and urban land cover . In contrast, 'Environment 2' is cold, medium- to small-sized streams with low conductivity and $\mathrm{pH}$, high surface water oxygen concentrations and less agricultural and urban land use within their catchment (Figure S4, Appendix S1). These two most diverging environments should be kept in mind for the following discussion, which evaluates if these encountered habitat diversities are mirrored in MA and MOX biogeography.

\subsection{MA and MOX biogeography and diversity}

\subsection{1 | Methanogenic archaea}

The four dominating MA families were comparable to those found in other sediment-related studies (Mach et al., 2015): Methanoregulaceae are ubiquitous and abundant in many habitats (Yang et al., 2017). They perform hydrogenotrophic methanogenesis similar to Methanobacteriaceae, the dominant archaeal group within lake ecosystems (Fan \& Xing, 2016). Across the studied streams, relative abundances of Methanosarcinaceae and Methanosaetaceae were negatively correlated, probably due to their shared capacity to perform acetoclastic methanogenesis and the resulting competition for the same niche. Of these, relative abundance of Methanosarcinaceae was higher in southern sampling sites, probably due to their versatile metabolic capabilities that allow them to adapt to the presence of other substrates besides acetate (Nazaries et al., 2013). Furthermore, they likely experience growth advantages over Methanosaetaceae, as acetate has been shown to be a major precursor of $\mathrm{CH}_{4}$ particularly under low-temperature conditions (Nozhevnikova et al., 2007).

The higher MA diversity and richness (Figure S2a, Appendix S1) at higher temperatures and larger catchment areas are probably due to a higher variability in nutrient sources and niches to be exploited. Similarly, lower anthropogenic influence generally limits the nutrient input into streams (Withers \& Lord, 2002), explaining the overall lower diversity and richness of MA in streams with higher natural catchment proportions.

\subsubsection{Methane-oxidizing microorganisms}

In accordance with previous studies, the predominant family of MOX across European streams was represented by Methylococcaceae (Costello et al., 2002), whereas a considerable number of OTUs (30) was unassigned Methylococcales (Figure 3). The order and the family are both type I MOB, while Methylobacteriaceae, the second most abundant family, is a representative of type II MOB, each type inhabiting a different niche. The general predominance of type I over type II MOB in freshwater sediments is consistent with previous findings (Costello et al., 2002). In contrast, the increased relative abundances of type II over type I MOB applied to all Spanish and Austrian samples (and GBR_1_1) was also reflected in the MOX community since the aforementioned streams clustered separately in the NMDS (Figure S3b, Appendix S1). For Spanish sites within mostly agricultural catchments, this might be explained by a potential eutrophication favouring type II MOB (Yang et al., 2019). Next to the aerobic type I and type II MOB, anaerobic $\mathrm{CH}_{4}$-oxidizing archaeal $\mathrm{Cd}$. Methanoperedens occupied anaerobic niches as corroborated by their higher abundance in deeper sediment layers. Deeper layers are typically supplied with less oxygen than the layers at the sediment-water interface, which also explains the higher abundance of the second anaerobic MOX representative, $C d$. Methylomirabilis. Accordingly, $\mathrm{Cd}$. Methanoperedens seems to benefit from higher surface areas (i.e. smaller particle sizes), leading to more anaerobic niches within those sites.

The diversity of MOX was mainly correlated with variables describing stream size (e.g. wetted stream width, stream area) and geographical latitude, with larger, southern streams exhibiting a higher diversity, probably due to a higher spatiotemporal variability in nutrients inputs of such streams draining larger catchments (Wilhelm et al., 2015).

\subsection{Climate and land use drive methanogenic and methanotrophic community compositions}

\subsection{1 | Methanogenic archaea}

Compared to MOX, MA showed a more homogeneous distribution across European streams, although PERMANOVA confirmed that there were significant differences among sampled streams. On 
the one hand, 'environment 1' streams showed MA communities mostly harbouring hydrogenotrophic members (Methanospirillaceae and Methanobacteriaceae) and the metabolically and physiologically versatile Methanosarcinaceae, which were negatively correlated with geographical latitude. On the other hand, acetoclastic Methanosaetaceae and hydrogenotrophic Methanocellaceae occurred in 'environment 2' streams (Figure S4, Appendix S1). The occurrence of methanogens in partly oxygenated soils and sediment has been acknowledged in upland soils (Angel et al., 2011), wetland sediments (Angle et al., 2017; Steinle et al., 2017) and lakes (Grossart et al., 2011) and in many cases they are dominated by the order Methanocella, due to its ability to detoxify reactive oxygen species (Angel et al., 2011).

Land use and land cover changes generally increased over the past decades and are mainly attributed to conversion of natural ecosystems to agricultural or urban areas (Hurtt et al., 2011). In that context, our results suggest that an ongoing increase of anthropogenic catchment alteration might result in altered MA communities with increased abundances of species characteristic for the defined 'environment 1'. Due to their diverse metabolic capacities and since their metabolic activity depends on the type and quantity of present substrates, altered $\mathrm{CH}_{4}-$ production rates are difficult to estimate. Our results suggest, however, that increasing stream temperatures lead to higher abundances of methanogens that use $\mathrm{CO}_{2}$ and $\mathrm{H}_{2}$ as substrates, a highly efficient $\mathrm{CH}_{4}$-production pathway (Lackner et al., 2018). On the other hand, relative abundances of Methanocellaceae and $\mathrm{Cd}$. Methanoflorentaceae, the latter being a hydrogenotrophic group dominating partially thawed and cold environments (Mondav et al., 2014), typically decrease with increasing stream temperatures, and might, thus, be negatively impacted by climate change.

Irrespective of water temperature and human impact, sediments of high-discharge streams featuring large catchments ('environment 3'; Figure S4, Appendix S1) harboured a high proportion of the methanogenic family Methanoregulaceae, dominated by the genera Methanolinea and Methanoregula. The large catchment areas may provide more diverse nutrients, promoting the aforementioned genera. In addition, the family Methanoregulaceae is used as a proxy for freshwater influence in the marine realm (Yang et al., 2017). Since the occurrences of this family were higher in high-discharge streams, Methanoregulaceae might be an indicator family of fresh water supply also in streams.

\subsection{2 | Methane-oxidizing microorganisms}

As the major biological sink for $\mathrm{CH}_{4}, \mathrm{MOX}$ attenuate the rivers' $\mathrm{CH}_{4}$ production within the water column and the sediment (Shelley et al., 2015). In this study, MOX communities were more distinct among streams than MA communities (Figure S3, Appendix S1). In addition, the sampling depth influenced the species composition, most probably due to the changed oxygen supply. Indeed, redundancy analysis identified oxygen as important environmental parameter shaping the MOX community composition. Typical representatives of oxygen-rich 'environment 2' streams were Methyloglobulus spp. and other representatives of the family Methylococcaceae (Figure 4), all belonging to type I MOB, performing the ribulose monophosphate pathway for carbon assimilation and requiring oxygen for $\mathrm{CH}_{4}$ activation (Kits et al., 2015). Oshkin et al. (2014) showed that type I MOB dominate cold floodplains of Siberian rivers and feature a large proportion of psychrotolerant methanotrophs, which fits to their higher abundance in the 'environment 2'. MOX utilize $\mathrm{CH}_{4}$ as their sole carbon and energy source at the sediment-water interface when oxygen from bottom waters is available as electron acceptor. In case of oxygen depletion and the presence of alternative electron acceptors, methane oxidation can be performed by anaerobically (ANME). The redox state, driven significantly by oxygen concentration, is a major environmental factor influencing microbial activity and diversity. ANME is mostly coupled to the reduction of iron, manganese, sulphate and nitrate (Boetius et al., 2000). Interestingly, $C d$. Methanoperedens was also a typical representative of oxygen-rich environments in this study, although it is an ANME methanotroph mediating nitrate-dependent anaerobic $\mathrm{CH}_{4}$ oxidation. It featured, however, higher abundances in the deeper sediment layer. This genus can counteract oxidative damage and adapt to regular oxygen exposure (Guerrero-Cruz et al., 2018).

Referring to the generally ongoing land use changes, increasing the agricultural and urban land cover in many European stream catchments (Hurtt et al., 2011), together with the accelerated warming of stream water, the here presented MOX community of 'environment 1 ' may gain importance in the future. This finding is supported by a recent study postulating that climate controls microbial functional gene diversity in streams at large spatial scales (Picazo et al., 2020). However, 'environment 1' did not harbour any conspicuous MOX except a few representatives of $C d$. Methylomirabilis and of the genus Methylogobulus (Methylococcaceae), probably reflecting the importance of other drivers that we did not measure. Rather, MOX communities formed an additional cluster including high-order and high discharge streams draining large catchments ('environment 3'; Figure S4, Appendix S1). This environment is preferentially inhabited by Methylocaldum spp., a genus able to fix $\mathrm{CO}_{2}$ in addition to $\mathrm{CH}_{4}$ (Group X), and Crenothrix spp., an important type I MOB described in Swiss lakes (Oswald et al., 2017).

\subsection{Gene abundances and their relation to PMO and PMP}

The logarithmic relationship between MA and MOB gene copies suggests a close dependency of $\mathrm{CH}_{4}$-oxidizing bacteria with the occurrence of methane-producing archaea (Figure 5). However, type I MOB showed a higher dependency on the occurrence of MA than type II MOB. One possible explanation is that some representatives of type II MOB (e.g. Methylocystis and all Methylobacteriaceae) are facultative methanotrophs and capable of growing on carbon sources other than $\mathrm{CH}_{4}$ (Dedysh \& Dunfield, 2011), while sufficient $\mathrm{CH}_{4}$ availability is a prerequisite for the proliferation of type I MOB. Further, the 'low-affinity' $\mathrm{CH}_{4}$ oxidation kinetics of type I methanotrophs, enabling 
high oxidation of $\mathrm{CH}_{4}$ at concentrations well above atmospheric levels might additionally explain this different relationship. In contrast, type II MOB has their niche in resource limited habitats (Cai et al., 2016).

According to the GLMM, organic carbon supply and thus nutrient availability within streams is positively related to the abundance of both, MA and MOB, while MA abundance additionally depends on sediment surface area. The latter dependency may reflect the general affinity of MA to anaerobic microhabitats formed to a higher degree in fine sediments (Higashino, 2013). The significant positive relationship between gene abundance and catchment area indicates that streams draining larger catchments receive more diverse nutrient species and provide higher nutrient availability and number of present niches for a wider range of organisms (Kosek et al., 2019).

Across European stream sediments, gene abundances of MA showed a significant positive correlation with PMP rates (Figure $5 d$ ), clearly linking the microbial abundances to its function by forming a LOG-LOG relationship. However, a slope of $<1$ suggests that with more methanogenic gene copies, the PMP is slightly lower as compared to smaller gene copy numbers. Thus, increased gene copy numbers within the investigated environmental DNA are not linearly correlated with activity. This is most probably due to extracellular DNA being produced with increasing activity, and/or due to changing counts of mcrAgene copies in the genome of different MA species (Nagler et al., 2018). Similarly, Mach et al. (2015) were not able to link PMP and mcrA-gene copy numbers in river sediments due to a regulation of PMP on the MA RNA or activity level rather than their absolute abundance.

In contrast to these findings, no significant relationship was found between PMO rates and MOB gene abundances. This finding, however, must be interpreted with care as not all MOX have been targeted with the qPCR and type Ib MOB (mostly represented by Methylocaldum spp. and $C d$. Methanoperedens) have not been quantified although they might represent an important share of all MOB according to the sequencing results. Besides this, there are several possible explanations for a lack of a clear relationship between PMO and MOB: (a) RNA or activity level of MOB might be a better indicator than absolute abundance (Mach et al., 2015), (b) alternative pathways might be carried out to gain energy since many MOB are non-obligatory $\mathrm{CH}_{4}$ oxidizers, (c) current methods are unable to distinguish aerobic from anaerobic $\mathrm{PMO}$, while the sediment composition might lead to a higher proportion of either aerobic or anaerobic PMO through differences in oxygen availability (Higashino, 2013). Hence, the different pathways and efficiencies of aerobic and anaerobic PMO might not allow a simple relationship between abundance and PMO.

\section{5 | Conclusions}

Our results demonstrate that the methanogenic and methanotrophic communities of the investigated European streams mainly group into three habitat types characterized by different abiotic conditions and catchment characteristics. Such distinguishable microbial communities suggest, that future climate- and land use changes may influence the prevailing microbes involved in the large-scale streamrelated $\mathrm{CH}_{4}$ cycle. Increasing water temperatures as consequence of climate change in combination with agricultural intensification and urban land use might thereby lead to higher abundances of highly efficient hydrogenotrophic $\mathrm{CH}_{4}$ producers (i.e. Methanospirillaceae, Methanobacteriaceae and Methanosarcinaceae), while the expected changes for $\mathrm{CH}_{4}$ consumers are less clear and seem to be more dependent on site specificities. In that context, this study gives a first overview of MA and MOX biogeographical patterns in stream sediments. However, additional in-depth studies are needed to further affirm our findings. The links between sediment organic carbon content and $\mathrm{MA} / \mathrm{MOB}$ abundance, and between MA abundances and PMP rates emphasize the importance of nutrient input for the $\mathrm{CH}_{4}$ cycle in streams, with potential consequences for the overall $\mathrm{CH}_{4}$ emissions from running waters. While many previous studies highlighted the general importance of nutrient effects on $\mathrm{CH}_{4}$ cycling (reviewed by Stanley et al., 2016), our results suggest, that these effects are mediated by changes within the microbial communities, whose composition and activity regulate this cycle.

\section{ACKNOWLEDGEMENTS}

We thank Jihyeon Kim, Christian Noss, Merlin Rosner and Haiying Xia for their support during the campaign preparations, laboratory work and raw data processing. Furthermore, we thank Sebastian Hupfauf, Andreas Lorke and Jeremy Wilkinson for their input regarding bioinformatics, study design and technical questions. The authors declare no conflict of interest. This study was financially supported by the German Research Foundation (grant BO 5050/1-1).

\section{DATA AVAILABILITY STATEMENT}

The datasets supporting the conclusions of this article are available in the NCBI repository under BioProject PRJNA578023, BioSample accessions from SAMN13046387 to SAMN13046482 and SRA IDs from $13,046,387$ to $13,046,482$ respectively (https://www.ncbi. nlm.nih.gov/sra/PRJNA578023). Sampling was conducted in compliance with collecting permits that applied for the various countries.

\section{ORCID}

Magdalena Nagler (iD https://orcid.org/0000-0002-4165-7290

\section{REFERENCES}

Angel, R., Claus, P., \& Conrad, R. (2011). Methanogenic archaea are globally ubiquitous in aerated soils and become active under wet anoxic conditions. The Isme Journal, 6, 847. https://doi.org/10.1038/ ismej.2011.141

Angle, J. C., Morin, T. H., Solden, L. M., Narrowe, A. B., Smith, G. J., Borton, M. A., Rey-Sanchez, C., Daly, R. A., Mirfenderesgi, G., Hoyt, D. W., Riley, W. J., Miller, C. S., Bohrer, G., \& Wrighton, K. C. (2017). Methanogenesis in oxygenated soils is a substantial fraction of wetland methane emissions. Nature Communications, 8, 1567. https://doi. org/10.1038/s41467-017-01753-4

Bates, D., Mächler, M., Bolker, B., \& Walker, S. (2015). Fitting linear mixed-effects models using Ime4. Journal of Statistical Software, 67, $1-48$. 
Bednařík, A., Blaser, M., Matoušů, A., Hekera, P., \& Rulík, M. (2017). Effect of weir impoundments on methane dynamics in a river Science of the Total Environment, 584-585, 164-174. https://doi. org/10.1016/j.scitotenv.2017.01.163

Bodmer, P., Attermeyer, K., Pastor, A., \& Catalán, N. (2019). Collaborative projects: Unleashing early career scientists power. Trends in Ecology \& Evolution, 34, 871-874. https://doi. org/10.1016/j.tree.2019.07.016

Bodmer, P., Wilkinson, J., \& Lorke, A. (2020). Sediment properties drive spatial variability of potential methane production and oxidation in small streams. Journal of Geophysical Research: Biogeosciences, 125. https://doi.org/10.1029/2019JG005213

Boetius, A., Ravenschlag, K., Schubert, C. J., Rickert, D., Widdel, F. Gieseke, A., Amann, R., Jørgensen, B. B., Witte, U., \& Pfannkuche, O. (2000). A marine microbial consortium apparently mediating anaerobic oxidation of methane. Nature, 407, 623-626. https://doi. org/10.1038/35036572

Bravo, A. G., Kothawala, D. N., Attermeyer, K., Tessier, E., Bodmer, P., Ledesma, J. L. J., Audet, J., Casas-Ruiz, J. P., Catalán, N., CauvyFraunié, S., Colls, M., Deininger, A., Evtimova, V. V., Fonvielle, J. A., Fuß, T., Gilbert, P., Herrero Ortega, S., Liu, L., Mendoza-Lera, C., ... Amouroux, D. (2018). The interplay between total mercury, methylmercury and dissolved organic matter in fluvial systems: A latitudinal study across Europe. Water Research, 144, 172-182. https://doi. org/10.1016/j.watres.2018.06.064

Cai, Y., Zheng, Y., Bodelier, P. L. E., Conrad, R., \& Jia, Z. (2016). Conventional methanotrophs are responsible for atmospheric methane oxidation in paddy soils. Nature Communications, 7, 11728. https://doi.org/10.1038/ncomms11728

Caporaso, J. G., Lauber, C. L., Walters, W. A., Berg-Lyons, D., Lozupone, C. A., Turnbaugh, P. J., Fierer, N., \& Knight, R. (2011). Global patterns of $16 \mathrm{~S}$ rRNA diversity at a depth of millions of sequences per sample. Proceedings of the National Academy of Sciences, 108, 4516-4522. https://doi.org/10.1073/pnas.1000080107

Chaudhary, P. P., Rulík, M., \& Blaser, M. (2017). Is the methanogenic community reflecting the methane emissions of river sediments?-comparison of two study sites. MicrobiologyOpen, 6, e00454.

Ciais, P., Sabine, C., Bala, G., Bopp, L., Brovkin, V., Canadell, J., Thornton, P. (2013) Carbon and other biogeochemical cycles. In T. F. Stocker, D. Qin, G.-K. Plattner, M. Tignor, S. K. Allen, J. Boschung, \& P. M. Midgley (Eds), Climate Change 2013: The physical science basis. Contribution of Working Group I to the Fifth Assessment Report of the Intergovernmental Panel on Climate Change. Intergovernmental Panel on Climate Change.

Costello, A. M., Auman, A. J., Macalady, J. L., Scow, K. M., \& Lidstrom, M. E. (2002). Estimation of methanotroph abundance in a freshwater lake sediment. Environmental Microbiology, 4, 443-450.

Crawford, J. T., Loken, L. C., West, W. E., Crary, B., Spawn, S. A., Gubbins, N., \& Stanley, E. H. (2017). Spatial heterogeneity of within-stream methane concentrations. Journal of Geophysical Research: Biogeosciences, 122, 1036-1048.

Crevecoeur, S., Ruiz-González, C., Prairie, Y. T., \& del Giorgio, P. A. (2019). Large-scale biogeography and environmental regulation of methanotrophic bacteria across boreal inland waters. Molecular Ecology, 28, 4181-4196.

Dedysh, S. N., \& Dunfield, P. F. (2011). Chapter three - facultative and obligate methanotrophs: How to identify and differentiate them. In A. C. Rosenzweig \& S. W. Ragsdale (Eds.), Methods in Enzymology (pp. 31-44). Academic Press.

Etminan, M., Myhre, G., Highwood, E. J., \& Shine, K. P. (2016). Radiative forcing of carbon dioxide, methane, and nitrous oxide: A significant revision of the methane radiative forcing. Geophysical Research Letters, 43, 12614-12623.

Ettwig, K. F., Butler, M. K., Le Paslier, D., Pelletier, E., Mangenot, S., Kuypers, M. M. M., \& Strous, M. (2010). Nitrite-driven anaerobic methane oxidation by oxygenic bacteria. Nature, 464, 543 .
Fan, X., \& Xing, P. (2016). Differences in the Composition of archaeal communities in sediments from contrasting zones of Lake Taihu. Frontiers in Microbiology, 7.

Grossart, H.-P., Frindte, K., Dziallas, C., Eckert, W., \& Tang, K. W. (2011). Microbial methane production in oxygenated water column of an oligotrophic lake. Proceedings of the National Academy of Sciences of the United States of America, 108, 19657-19661.

Guerrero-Cruz, S., Cremers, G., van Alen, T. A., Op den Camp, H. J. M., Jetten, M. S. M., \& Vaksmaa, A. (2018). Response of the anaerobic methanotroph Candidatus methanoperedens nitroreducens" to oxygen stress. Applied and Environmental Microbiology, 84, e01832-e1918.

Higashino, M. (2013). Quantifying a significance of sediment particle size to hyporheic sedimentary oxygen demand with a permeable stream bed. Environmental Fluid Mechanics, 13, 227-241.

Hupfauf, S., Etemadi-Shalamzari, M., Fernández-Delgado Juárez, M., Gómez-Brandón, M., Insam, H., \& Podmirseg, S. M. (2020). CoMA an intuitive and user-friendly pipeline for amplicon-sequencing data analysis. Plos ONE. Available at: https://www.uibk.ac.at/micro biology/services/coma.html accessed 29.10.2020. https://doi. org/10.1371/journal.pone.0243241.

Hurtt, G. C., Chini, L. P., Frolking, S., Bett, R. A., Feddema, J., Fischer, G., \& Wang, Y. P. (2011). Harmonization of land-use scenarios for the period 15002100: 600 years of global gridded annual land-use transitions, wood harvest, and resulting secondary lands. Climatic Change, 109, 117-161.

Jaeger, B. (2017) 2glmm: Computes R Squared for Mixed (Multilevel) Models.

Kalyuzhnaya, M. G., Gomez, O. A., \& Murrell, J. C. (2019). The Methaneoxidizing bacteria (Methanotrophs). In T. J. Mcgenity (Ed.), Taxonomy, Genomics and Ecophysiology of Hydrocarbon-Degrading Microbes (pp. 1-34). Springer International Publishing.

Kassambra, A. (2018) ggpubr: "ggplot2" Based Publication Ready Plots.

Kassambra, A., \& Mundt, F. (2017) factoextra: Extract and Visualize the Results of Multivariate Data Analyses.

Kits, K. D., Campbell, D. J., Rosana, A. R., \& Stein, L. Y. (2015). Diverse electron sources support denitrification under hypoxia in the obligate methanotroph Methylomicrobium album strain BG8. Frontiers in Microbiology, 6

Kolb, S., Knief, C., Stubner, S., \& Conrad, R. (2003). Quantitative detection of methanotrophs in soil by novel pmoA-targeted real-time PCR assays. Applied and Environmental Microbiology, 69, 2423-2429.

Kosek, K., Luczkiewicz, A., Kozioł, K., Jankowska, K., Ruman, M., \& Polkowska, Ż. (2019). Environmental characteristics of a tundra river system in Svalbard. Part 1: Bacterial abundance, community structure and nutrient levels. Science of the Total Environment, 653, 1571-1584.

Lackner, N., Hintersonnleitner, A., Wagner, A. O., \& Illmer, P. (2018). Hydrogenotrophic methanogenesis and autotrophic growth of Methanosarcina thermophila. Archaea, 2018, 4712608.

Lê, S., Josse, J., \& Husson, F. (2008). FactoMineR: An R package for multivariate analysis. Journal of Statistical Software, 1(1).

Mach, V., Blaser, M. B., Claus, P., Chaudhary, P. P., \& Rulík, M. (2015). Methane production potentials, pathways, and communities of methanogens in vertical sediment profiles of river Sitka. Frontiers in Microbiology, 6.

Machalett, B., Oches, E. A., Frechen, M., Zöller, L., Hambach, U., Mavlyanova, N. G., \& Endlicher, W. (2008). Aeolian dust dynamics in central Asia during the Pleistocene: Driven by the long-term migration, seasonality, and permanency of the Asiatic polar front. Geochemistry, Geophysics, Geosystems, 9, https://doi.org/10.1029/2007GC001938

Mondav, R., Woodcroft, B. J., Kim, E.-H., McCalley, C. K., Hodgkins, S. B., Crill, P. M., \& Tyson, G. W. (2014). Discovery of a novel methanogen prevalent in thawing permafrost. Nature Communications, 5, 3212.

Nagler, M., Podmirseg, S. M., Griffith, G. W., Insam, H., \& AscherJenull, J. (2018). The use of extracellular DNA as a proxy for specific microbial activity. Applied Microbiology and Biotechnology, 102, 2885-2898. 
Nakagawa, S., \& Schielzeth, H. (2012). A general and simple method for obtaining $\mathrm{R}^{2}$ from generalized linear mixed-effects models. Methods in Ecology and Evolution, 4, 133-142.

Nazaries, L., Murrell, J. C., Millard, P., Baggs, L., \& Singh, B. K. (2013). Methane, microbes and models: Fundamental understanding of the soil methane cycle for future predictions. Environmental Microbiology, 15, 2395-2417.

Nozhevnikova, A. N., Nekrasova, V., Ammann, A., Zehnder, A. J. B., Wehrli, B., \& Holliger, C. (2007). Influence of temperature and high acetate concentrations on methanogenensis in lake sediment slurries. FEMS Microbiology Ecology, 62, 336-344.

Oksanen, J., Blanchet, F. G., Friendly, M., Kindt, R., Legendre, P. D. M., Minchin, P. R., O'Hara, B., Simpson, G. L., Solymos, P., Stevens, H., \& Wagner, H. (2019). vegan: Community Ecology Package.

Oshkin, I. Y., Wegner, C. C. L., Glagolev, M. V., Fillipov, I. V., Pimenov, N. V., Liesack, W., \& Dedysh, S. N. (2014). Gammaproteobacterial methanotrophs dominate cold methane seeps in floodplains of West Siberian Rivers. Microbial Ecology, 80, 5944-5954.

Oswald, K., Graf, J. S., Littmann, S., Tienken, D., Brand, A., Wehrli, B., \& Milucka, J. (2017). Crenothrix are major methane consumers in stratified lakes. The Isme Journal, 11, 2124

Oswald, K., Milucka, J., Brand, A., Littmann, S., Wehrli, B., Kuypers, M. M. M., \& Schubert, C. J. (2015). Light-Dependent Aerobic methane oxidation reduces methane emissions from seasonally stratified lakes. PLoS One, 10, e0132574.

Picazo, F., Vilmi, A., Aalto, J., Soininen, J., Casamayor, E. O., Liu, Y., \& Wang, J. (2020). Climate mediates continental scale patterns of stream microbial functional diversity. Microbiome, 8, 92.

Praeg, N., Schwinghammer, L., \& Illmer, P. (2020). Larix decidua and additional light affect the methane balance of forest soil and the abundance of methanogenic and methanotrophic microorganisms. FEMS Microbiology Letters, 366

R Core Team (2018). R: A language and environment for statistical comput ing. R Foundation for Statistical Computing.

Schloss, P. D., Westcott, S. L., Ryabin, T., Hall, J. R., Hartmann, M., Hollister, E. B., \& Weber, C. F. (2009). Introducing mothur: OpenSource, platform-independent, community-supported software for describing and comparing microbial communities. Applied and Environmental Microbiology, 75, 7537-7541.

Shelley, F., Abdullahi, F., Grey, J., \& Trimmer, M. (2015). Microbial methane cycling in the bed of a chalk river: Oxidation has the potential to match methanogenesis enhanced by warming. Freshwater Biology, 60, 150-160.

Šmilauer, P., \& Lepš, J. (2014). Multivariate Analysis of Ecological Data using CANOCO 5 (2nd ed.). Cambridge University Press.

Stanley, E. H., Casson, N. J., Christel, S. T., Crawford, J. T., Loken, L. C., \& Oliver, S. K. (2016). The ecology of methane in streams and rivers: Patterns, controls, and global significance. Ecological Monographs, 86, 146-171. https://doi.org/10.1890/15-1027

Steinle, L., Maltby, J., Treude, T., Kock, A., Bange, H. W., Engbersen, N., Zopfi, J., Lehmann, M. F., \& Niemann, H. (2017). Effects of low oxygen concentrations on aerobic methane oxidation in seasonally hypoxic coastal waters. Biogeosciences, 14, 1631-1645. https://doi. org/10.5194/bg-14-1631-2017

Steinle, L., Schmidt, M., Bryant, L., Haeckel, M., Linke, P., Sommer, S., \& Niemannn, H. (2016). Linked sediment and water-column methanotrophy at a man-made gas blowout in the North Sea: Implications for methane budgeting in seasonally stratified shallow seas. Limnology and Oceanography, 61, S367-S386.

Strahler, A. N. (1952). Hypsometric (area-altitude) analysis of erosional topography. GSA Bulletin, 63, 1117-1142.

Su, G., Niemann, H., Steinle, L., Zopfi, J., \& Lehmann, M. F. (2019). Evaluating radioisotope-based approaches to measure anaerobic methane oxidation rates in lacustrine sediments. Limnology and Oceanography: Methods, 17, 429-438.

Trimmer, M., Shelley, F. C., Purdy, K. J., Maanoja, S. T., Chronopoulou, P.-M., \& Grey, J. (2015). Riverbed methanotrophy sustained by high carbon conversion efficiency. The ISME Journal, 9, 2304-2314. https://doi.org/10.1038/ismej.2015.98

Wei, T., Simko, V., Levy, M., Xie, Y., Jin, Y., \& Zemla, J. (2017). Corrplot: Visualisation of a Correlation Matrix.

Wilhelm, L., Besemer, K., Fragner, L., Peter, H., Weckwerth, W., \& Battin, T. J. (2015). Altitudinal patterns of diversity and functional traits of metabolically active microorganisms in stream biofilms. The Isme Journal, 9, 2454. https://doi.org/10.1038/ismej.2015.56

Wilkinson, J., Bodmer, P., \& Lorke, A. (2019). Methane dynamics and thermal response in impoundments of the Rhine River, Germany. Science of the Total Environment, 659, 1045-1057. https://doi.org/10.1016/j.scitotenv.2018.12.424

Withers, P. J. A., \& Lord, E. I. (2002). Agricultural nutrient inputs to rivers and groundwaters in the UK: Policy, environmental management and research needs. Science of the Total Environment, 282-283, 9-24. https://doi.org/10.1016/S0048-9697(01)00935-4

Yang, S., Liebner, S., Winkel, M., Alawi, M., Horn, F., Dörfer, C., \& Wagner, D. (2017). In-depth analysis of core methanogenic communities from high elevation permafrost-affected wetlands. Soil Biology and Biochemistry, 111, 66-77.

Yang, Y., Chen, J., Tong, T., Li, B., He, T., Liu, Y., \& Xie, S. (2019). Eutrophication influences methanotrophic activity, abundance and community structure in freshwater lakes. Science of the Total Environment, 662, 863-872.

\section{BIOSKETCH}

Magdalena Nagler is an early career postdoctoral microbiologist interested in the description of microbial biogeographical patterns with a special focus on anaerobic pro- and eukaryota including methanogenic archaea and anaerobic fungi. Furthermore, she studies the influence of extracellular DNA on the indicator quality of environmental DNA in ecological assessments.

Author contribution: MN analysed the DNA samples, performed bioinformatics and statistics and wrote the major part of the manuscript, NP performed laboratory work, performed bioinformatics and statistics, helped with the interpretation of the results and wrote parts of the manuscript, GHN and NC performed statistical tests and wrote parts of the manuscript, KA generated the conceptual figures and gave major inputs to the manuscript, BM performed laboratory analyses, LS performed laboratory analyses and wrote parts of the manuscript, PG performed language editing, and PB coordinated the project, was responsible for the study design, wrote major parts of the manuscript and discussed and interpreted the results. Besides NP, BM and LS, all authors selected sites, participated in the sampling campaign and data collection, and contributed to the different versions of the manuscript

\section{SUPPORTING INFORMATION}

Additional supporting information may be found online in the Supporting Information section.

How to cite this article: Nagler M, Praeg N, Niedrist GH, et al. Abundance and biogeography of methanogenic and methanotrophic microorganisms across European streams.

J Biogeogr. 2021;48:947-960. https://doi.org/10.1111/jbi.14052 